\title{
ModificaCiOneS EN LA CORTEZA DE PROSOPIS LAEVIGATA POR EL ESTABLECIMIENTO DE TILLANDSIA RECURVATA
}

\author{
Silvia Aguilar-RodríGuez ${ }^{1,5}$, Teresa Terrazas ${ }^{4}$, Ernesto Aguirre-LeÓn ${ }^{2}$ Y \\ Ma. Elena HUIDOBRO-SALAS ${ }^{3}$ \\ 'Unidad de Morfología y Función, Laboratorio de Botánica, ${ }^{2}$ UBIPRO, ${ }^{3}$ Herbario IZTA. \\ FES-Iztacala, Universidad Nacional Autónoma de México, \\ Av. de los Barrios 1, Los Reyes Iztacala, Tlalnepantla, A.P. 314, Edo. de México, 54090, México. \\ ${ }^{4}$ Instituto de Biología, Universidad Nacional Autónoma de México, \\ Apdo. Postal 70-233, México 04510, D.F. México. \\ ${ }^{5}$ Autor para correspondencia. Correo-e: siagro@campus.iztacala.unam.mx
}

\begin{abstract}
Resumen: El crecimiento de Tillandsia recurvata sobre las ramas de Prosopis laevigata parece causar varios grados de daño. El objetivo de este trabajo fue estudiar y comparar los posibles cambios anatómicos en la corteza del forofito provocados por la interacción con la epifita. En la corteza carente de la epifita se distinguen floema no colapsado y floema colapsado, córtex y peridermis, semejante a lo descrito para otras especies de leguminosas. La fijación de T. recurvata en la corteza de $P$. laevigata provoca diferentes respuestas en su estructura anatómica, afectando diferentes tejidos. Los cambios se manifiestan por la formación de súber de reacción y de células con contenido obscuro, probablemente de naturaleza fenólica y como barrera química al establecimiento de enfermedades. Cuando la fijación de la epifita es mayor, se observan diferentes grados de invaginación que pueden llegar a la madera y alterar su patrón típico, es decir, causar una reducción en el número y diámetro de los vasos. El impacto que la epifita causa sobre el forofito puede favorecer el ataque de patógenos en los tejidos de los hospederos.
\end{abstract}

Palabras clave: anatomía, corteza, epifita, forofito, Prosopis laevigata, Tillandsia recurvata.

\begin{abstract}
The growth of Tillandsia recurvata on Prosopis laevigata branches seems to cause various degrees of damage. In this study the possible anatomical modifications in the bark of the phorophyte $P$. laevigata caused by the epiphyte $T$. recurvata are studied. When the epiphyte has not yet established, the bark of $P$. laevigata displays the typical distinctive non-collapsed and collapsed phloem, cortex and periderm similar to those described for other leguminous species. However, once T. recurvata is established on $P$. laevigata branches there are modifications in various tissues: the occurrence of a wound periderm and the occlusion of cortex and collapsed phloem cells with dark extractives as a chemical barrier for defence against infections. When the epiphyte has been vigorously attached for a long time to the bark, the damage is deeper in the tissues, thus affecting the wood. The most notorious change in the wood is related to a different distribution of secondary xylem cells and a reduction in the number and diameter of vessels. The impact of the epiphyte in the phorophyte may favor the occurrence of pathogen attacks in the phorophyte tissues.
\end{abstract}

Key words: anatomy, bark, epiphyte, phorophyte, Prosopis laevigata, Tillandsia recurvata.

G eneralmente el epifitismo se entiende como una relación inocua entre dos especies, para la que se describe una trama ecológica compleja que mantiene la diversidad biológica en un equilibrio interactivo (Benzing, 1990; Waechter, 1998). Sin embargo, se ha reportado que la sobrepoblación de Tillandsia recurvata L. sobre las ramas de Parkinsonia praecox es causa de modificaciones en la arquitectura y el crecimiento de individuos en esta especie
(Montaña et al., 1997; Páez-Gerardo, 2005). Tillandsia recurvata o musgo bola, como se le conoce comúnmente, tiene un éxito reproductivo elevado en diversos árboles y arbustos de las zonas secas del país, pero aparentemente éste se hace más notorio en ambientes perturbados, cuando la epifita cubre grandes áreas de las ramas de árboles y arbustos (Montaña et al., 1997; Páez-Gerardo, 2005). Los efectos de $T$. recurvata sobre la estructura anatómica de la 
corteza de Parkinsonia praecox se estudiaron en un trabajo previo, observándose que en la superficie de las ramas de $P$. praecox se produce un súber de lesión, que conlleva a la pérdida de los tejidos epidérmico y fotosintético de la corteza (Páez-Gerardo et al., 2005).

En las zonas secas de México Prosopis laevigata (Humb. et Bonpl. ex Willd) M.C.Johnst crece cubriendo grandes extensiones que revisten importancia económica. Tanto la corteza como la madera, además de las hojas y los frutos de algunas especies de Prosopis, se utilizan para el consumo humano y del ganado. Además, la resistencia a la sequía y la propagación exitosa las hacen candidatas ideales para la reforestación de estas zonas (Galera, 2000). En observaciones de campo se ha detectado que P. laevigata llega a hospedar numerosas plantas de Tillandsia recurvata en sus ramas. Tomando en cuenta los estudios existentes sobre las alteraciones en la corteza de Parkinsonia praecox, causados por T. recurvata (Páez-Gerardo et al., 2005) y a que en ella se llevan a cabo los procesos vitales para la supervivencia de los organismos, se hace necesario investigar cuál es el posible efecto de esta relación. En este trabajo se evaluaron los cambios anatómicos en la corteza de Prosopis laevigata provocados por su interacción con Tillandsia recurvata.

\section{Materiales y método}

Las muestras de Prosopis laevigata se obtuvieron de zonas ocupadas por matorral xerófilo en los estados de Hidalgo, Puebla y San Luis Potosí. En estos sitios se detectaron individuos de $P$. laevigata con ramas sobrepobladas por la epifita. Se seleccionaron ramas con 1-3 cm de diámetro, libres de la bromeliácea (figura 1a), así como otros con establecimiento de la misma (figura 1b). En este segundo caso, las ramas fueron elegidas considerando el establecimiento de la epifita en áreas de corteza sin espinas, lenticelas o alguna cicatriz como lesiones o restos de crecimientos. Todas las ramas estudiadas fueron jóvenes, con diámetros $3 \mathrm{~cm}$, debido a que las ramas gruesas presentan un ritidoma con acumulación de numerosas peridermis que hacen más difícil evaluar la interacción epifita-forofito.

Se recolectaron 20 ramas de dife rentes individuos. Segmentos de estas ramas de aproximadamente $3 \mathrm{~cm}$ de longitud se fijaron en formol-alcohol-ácido acético glacial (0.5:9:0.5) durante $48 \mathrm{~h}$; posteriormente se lavaron con agua corriente y se mantuvieron hidratadas en una solución de glicerina:alcohol:agua $(1: 1: 1)$ hasta su procesamiento en laboratorio. Los cortes se realizaron utilizando un micrótomo de deslizamiento y se obtuvieron secciones de 20-25 $\mu \mathrm{m}$ de grosor de los planos transversal y radial incluyendo la corteza; en el plano tangencial se realizaron cortes seriados de la peridermis a la madera siguiendo la técnica convencional para maderas (Johansen, 1940). Para la obtención de disociados se empleó la solución de Jeff rey
(Johansen, 1940). La descripción de la corteza se realizó de acuerdo con lo propuesto por Trockenbrodt (1990) y para algunos aspectos sobre la anatomía de la madera se consideraron las recomendaciones del IAWA Committee (1989). Las descripciones y mediciones de los elementos celulares de la corteza y la madera se realizaron con un analizador de imágenes (Leica Microsystems, 2002). Se realizaron 25 mediciones de cada carácter por muestra (diámetro y número de vasos $/ \mathrm{mm}^{2}$ ), presentándose en la descripción los valores de la media, una desviación estándar y entre paréntesis los valores mínimo y máximo.

\section{Resultados}

Descripción anatómica de la corteza de Prosopis laevigata. En la sección transversal de las ramas carentes de la epifita se distinguen cuat rozonas: floema no colapsado y floema colapsado, una zona cortical (córtex) y la peridermis (figura 1c).

- Floema. El floema no colapsado y el colapsado están compuestos por elementos de tubo criboso (ETC), células acompañantes (CA), parénquima axial (PA) y radial (radios, R).

- Floema no colapsado. Se organiza en dos estratos separados por una banda discontinua de esclerénquima, que se interrumpe por los radios (figura 1c). En el floema más cercano a la zona cambial, las células se ordenan radialmente y van perdiendo esta disposición conforme se alejan del cámbium vascular. Los ETC, en vista transversal, son de forma rectangular (angulosos), con $11 \pm$ $1.34 \mu \mathrm{m}(9.5-14.6 \mu \mathrm{m})$ de diámetro y con placas cribosas compuestas; las CA se localizan en las paredes radiales de los ETC (figura 1d). El PA se organiza en bandas tangenciales cortas interrumpidas por los radios. Los $\mathrm{R}$ en esta zona son de curso recto, con cristales prismáticos. El esclerénquima está formado por fibras y se organiza en conjuntos tangenciales, observándose en vista transversal una banda discontinua separada por los radios de parénquima.

- Floema colapsado. A partir de la segunda banda discontinua de esclerénquima se distingue la zona de floema colapsado (figura 1e). Los ETC se colapsan, observándose a manera de pequeños estratos que se separan en sus márgenes tangenciales por el PA. El PA se organiza en hileras tangenciales y forma grupos de una a tres células de grosor, las que se asocian con las bandas cortas de esclerénquima. Este PA se puede presentar a ambos lados o rodear parcialmente a las bandas de esclerénquima. Las paredes de las células más cercanas a la peridermis se lignifican y son de mayor tamaño que las que se encuentran más internas; además, en los márgenes de los grupos las células se dilatan hasta confundirse con los radios. Los $\mathrm{R}$ siguen un curso sinuoso al atravesar la segunda o tercera banda discontinua de esclerénquima, se dilatan conforme 

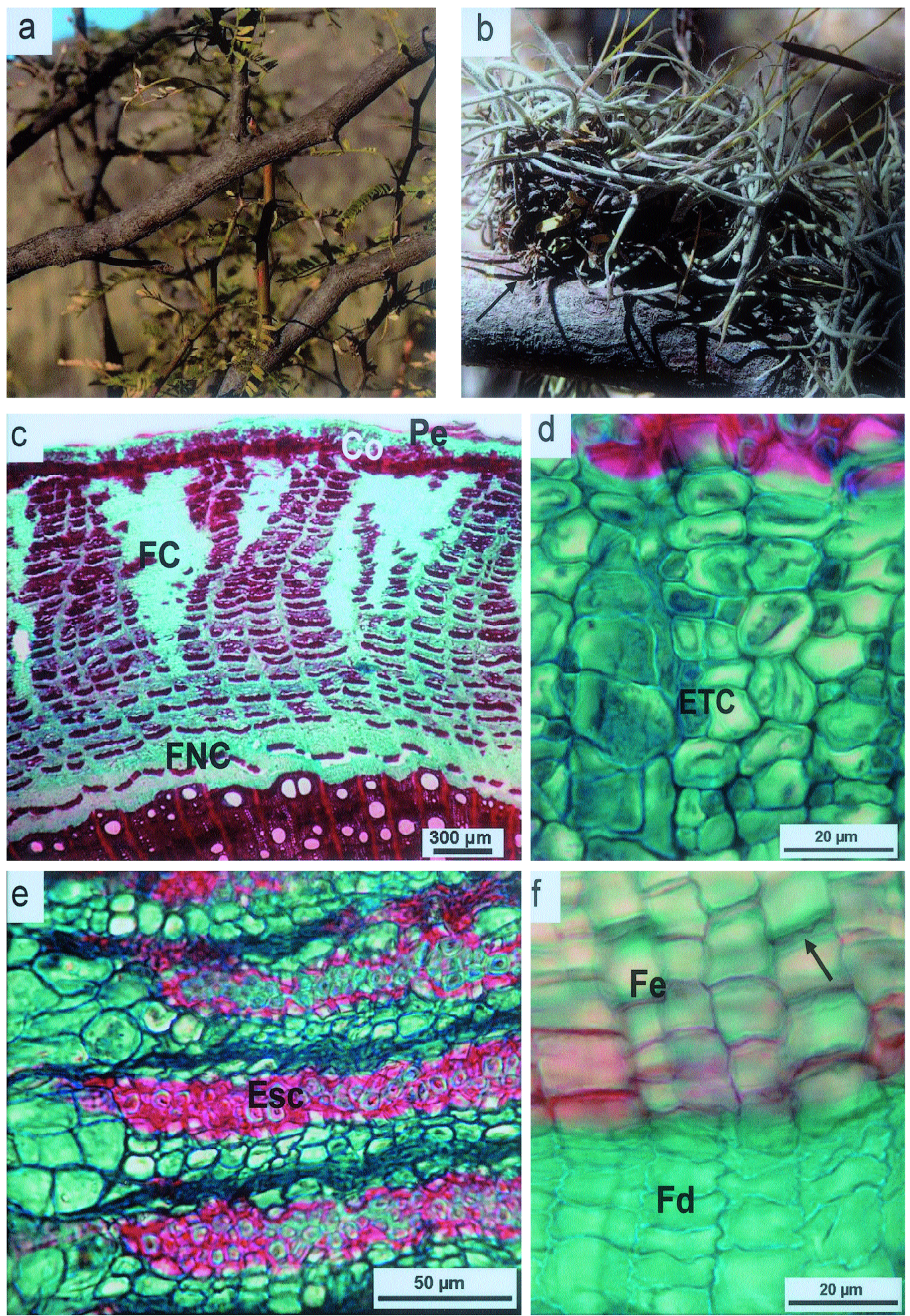

Figura 1. Prosopis laevigata. a-b. Ramas. a. Libres de T. recurvata. b. Con varios individuos de T. recurvata; notar raíces de un individuo en el extremo izquierdo adheridas a la corteza lisa de la rama (flecha). c-f. Cortes transversales de la corteza. c. Vista general de la corteza mostrando floema no colapsado (FNC), floema colapsado (FC), córtex (Co) y peridermis (Pe). d. Elementos de tubo criboso (ETC) en el floema no colapsado cercano al cámbium vascular. e. Bandas de esclerénquima (Esc) en el floema colapsado. f. Peridermis; notar las paredes tangenciales del felema (Fe) con mayor engrosamiento que las periclinales (flecha) y con proyecciones hacia el lumen celular y células de la felodermis $(\mathrm{Fd})$ también con paredes delgadas. 

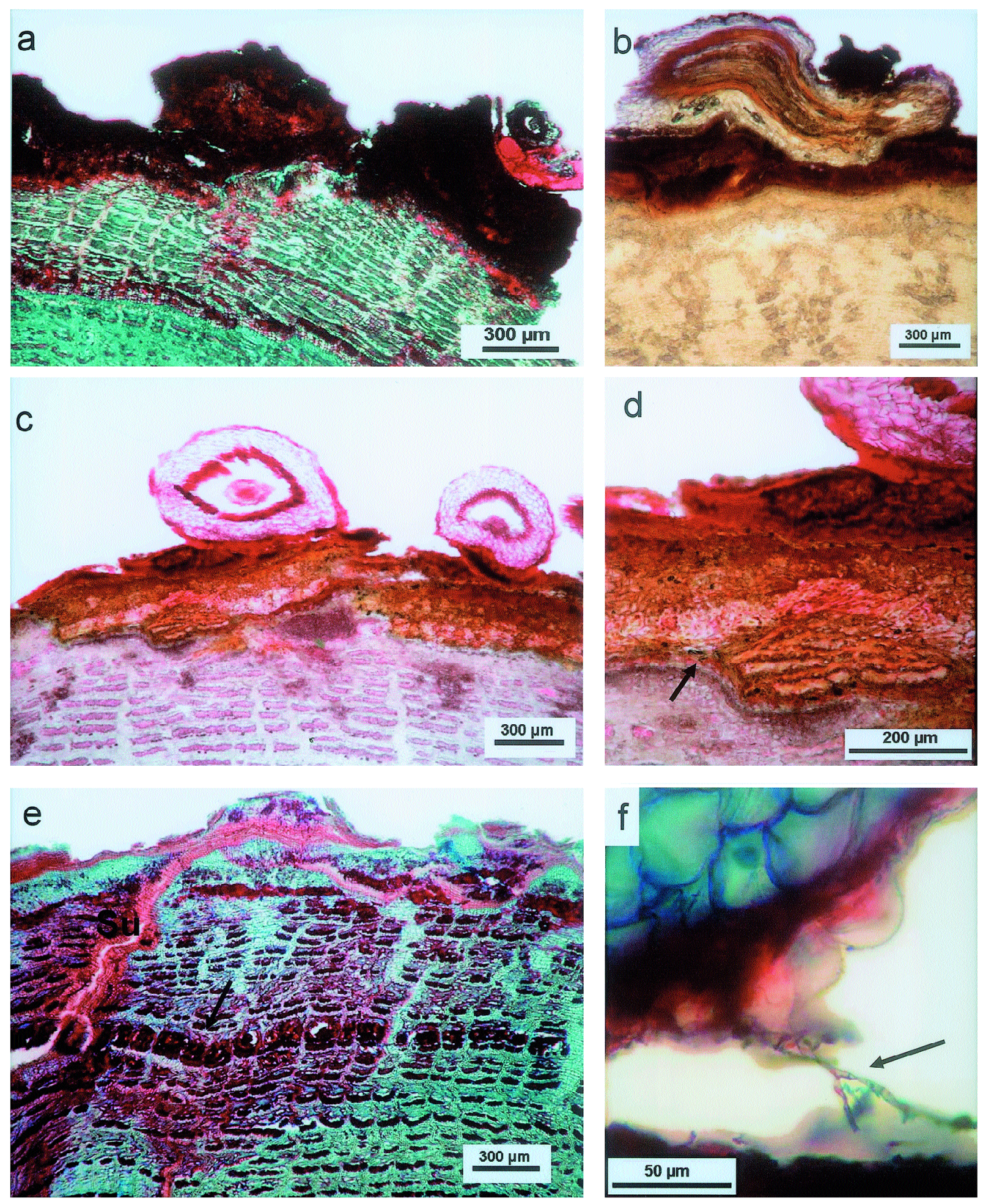

Figura 2. Cortes transversales de la zona de interacción de la raíz de Tillandsia recurvata con la corteza de rama de Prosopis laevigata. a. Raíz de T. recurvata sobre corteza que muestra contenido obscuro. b. Vista longitudinal de la raíz sobre córtex. c. Vista transversal de la raíz de T. recurvata. d. Córtex con la formación de capas múltiples de células colapsadas con abundante depósitos de color amarillento y el desarrollo de peridermis de daño (flecha). e. células con contenido obscuro (flecha) en las ramas de P. laevigata mostrando los tejidos inmediatos al sitio donde existe una fuerte fijación de $T$. recurvata y desarrollo de súber ( $\mathrm{Su}$ ). f. Hifa presente en la interfase raízcorteza (flecha). 
se acercan a la peridermis y su presencia se limita al borde con una banda ininterrumpida de esclerénquima, formada de esclereidas. Las bandas de esclerénquima en esta zona son más cortas que las de estratos inferiores debido al ensanchamiento de los radios.

- Córtex. En las ramas jóvenes, esta región se delimita en su parte inferior por la banda continua de esclerénquima (figura 1c). Hacia la peridermis se localizan células de parénquima, de forma rectangular alargada, con las paredes anticlinales cortas. También se localizan conjuntos de células con las paredes que inician la acumulación de pared secundaria donde se deposita lignina; en algunos casos además existen esclereidas y fibras. En las células de parénquima y en las esclerosadas se distinguen cristales prismáticos en su interior.

- Peridermis. Está formada por felodermis, felógeno y felema (súber), organizados en hileras radiales (figura 1f). El felógeno se arregla en una sola hilera de células comprimidas radialmente, con paredes delgadas. La felodermis está compuesta por cinco o más estratos de células, con paredes delgadas. En el felema se observan numerosos estratos, en ocasiones más de 15; sus paredes tangenciales están más engrosadas que las radiales y en ocasiones presentan proyecciones hacia el lumen celular. En algunas zonas se observa ritidoma, donde se acumulan más de una peridermis y parches de floema secundario colapsado que separan el parénquima cortical.

Cambios anatómicos en la corteza de P. laevigata por la fijación de T. recurvata. Las zonas de las ramas de P. laevi gata donde se establece $T$. recurvata se caracterizan macroscópicamente por una gradación de cambios, que van desde los no apreciables a simple vista, pasando por modificaciones leves, hasta cambios notables en la corteza. Los cambios microscópicos de la corteza que afectan exclusivamente a la peridermis se caracterizan por la modificación en su estructura típica, perdiéndose la organización en hileras radiales de las células que constituyen a la peridermis (figura 2a-c). Es frecuente observar entre las raíces de $T$. recurvata y la corteza una banda de contenidos obscuros (figura 2a,d); además, en el córtex se presenta una zona de células colapsadas con gran cantidad de sustancias de color amarillento (figura 2d). Por debajo de ella existen células dispuestas radialmente, de forma rectangular en sección transversal, con contenido obscuro (figura 2e). Continuando hacia el cámbium vascular hay células de forma redondeada con contenido también obscuro y por debajo de ellas se observan grupos de esclereidas que llegan a abarcar porciones externas del floema colapsado. Limítrofe a esta zona se desarrolla una banda de células suberizadas por debajo de la cual se continúa el floema secundario.

Las raíces de la epifita se distingue anatómicamente por presentar una epidermis, velamen, exodermis multiestrati- ficada formada por células con paredes engrosadas, varios estratos de parénquima y el tejido vascular (figura 2c). En algunos casos se aprecian hifas en la interfase raíz-corteza (figura 2f).

En otras áreas de la corteza, donde la fijación de la epifita es mayor, se llegan a observar diferentes grados de invaginación que pueden llegar a la madera (figura 3a, c, d). Cuando sólo se afecta la corteza, las invaginaciones se caracterizan por la formación de hendiduras en donde el floema colapsado (en diferentes grados) se separa, perdiendo su continuidad: en ellas se forma una zona de súber (figura 3a). En la región en donde se forman invaginaciones profundas todo el tejido floemático se divide y las zonas distintivas de la corteza (floema no colapsado, colapsado y córtex) no se distinguen (Figura 3c, d, e). En este caso, los cambios producidos en los tejidos próximos al sitio de fijación de la raíz de la epifita son: una peridermis de daño, una proliferación de parénquima cercana al cámbium vascular y células parenquimatosas asociadas a bandas de esclerénquima que se dividen y expanden en el floema colapsado. El lumen celular de estas células está ocluido por un contenido obscuro (Figura 2e).

La estructura anatómica de la madera de $P$. laevigata se caracteriza por su porosidad anular con abundantes fibras gelatinosas en bandas (Figura 3b). Esta estructura también se observa modificada en su patrón típico; el número de vasos en la madera no afectada es de $65 / \mathrm{mm}^{2}$, con un diámetro tangencial promedio en los vasos grandes de $70.0 \pm$ $15.8 \mu \mathrm{m}(47.3-98.5 \mu \mathrm{m})$ y en los vasos angostos de 21.3 $\pm 5.1 \mu \mathrm{m}$ (15.8 - $29.5 \mu \mathrm{m})$; sin embargo, en las zonas afectadas tanto el número como el diámetro de los vasos disminuyen considerablemente, siendo frecuente observar de 3 a 8 vasos $/ \mathrm{mm}^{2}$, con un diámetro tangencial de $8 \mu \mathrm{m}$. Además, las fibras pierden su orientación y orden, apreciándose una hipertrofia tisular generalizada en esta área (figura 3d, e). Este comportamiento es poco frecuente y se presentó en un caso en que la epifita había permanecido adherida durante varios años.

\section{Discusión}

Características macroscópicas de la corteza. Prosopis lae vigata es uno de los forofitos sobre los que crece exitosamente $T$. recurvata. Las ramas del interior de la copa de los arbustos parecen tener mayor probabilidad de ser habitadas por esta epifita que cualquier otra parte del individuo (García-Franco et al., 2007), probablemente como una protección contra la desecación por el microclima que se establece (García-Franco et al., 2007). No obstante que Samaniego (2002) menciona que $T$. recurvata se puede instalar en ramas lisas o rugosas, el trabajo de campo nos permitió apreciar la afinidad que tienen las "bolas" por crecer en los sitios donde se presentan espinas y rugosidades, espacios que facilitan la fijación de las semillas de la epifi- 

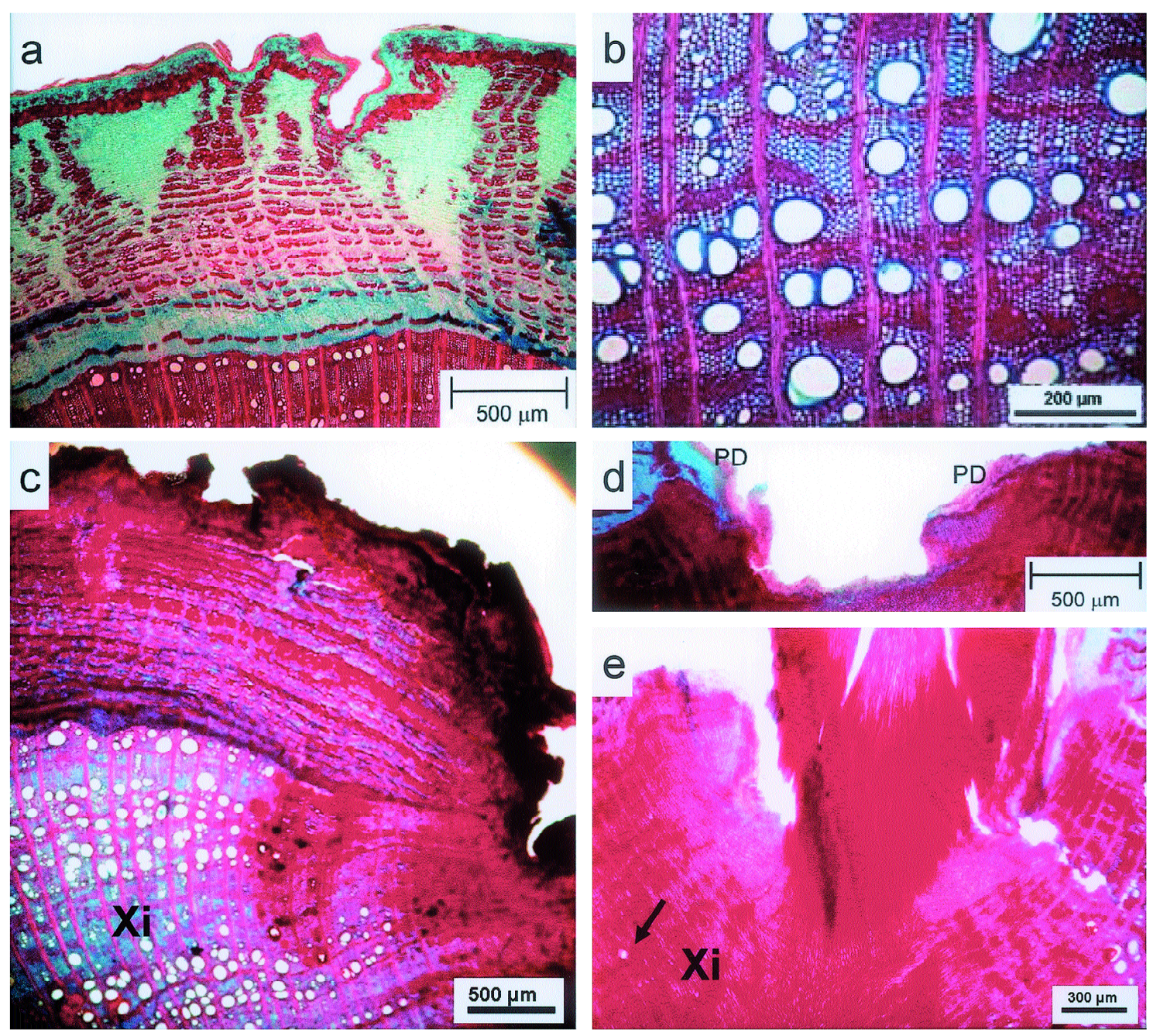

Figura 3. Cortes transversales de ramas de Prosopis laevigata con daños profundos por la fijación de Tillandsia recurvata. a. Invaginaciones sólo en la corteza. b. Xilema secundario sin alteraciones. c. Invaginación profunda en donde el floema pierde su continuidad y el xilema secundario (Xi) se modifica. d. Peridermis (PD) limitando la invaginación. e. Xilema secundario (Xi) con hipertrofia generalizada y escasos vasos (flecha).

ta, lo que en muchos casos hizo difícil la obtención de ramas jóvenes con epifitas que tuvieran la corteza libre de espinas, lenticelas o de alguna cicatriz, como lesiones o restos de crecimiento. La morfología externa de la corteza de $P$. laevigata varía de acuerdo con su madurez. En las ramas con diámetros de $1 \mathrm{a} 3 \mathrm{~cm}$ es lisa y de color pardo; sin embargo, se observan espinas axilares prominentes (Ffolliott y Thames, 1983), en donde es frecuente observar a la planta creciendo. La corteza de ramas mayores de $5 \mathrm{~cm}$ y del tronco es escamosa a profundamente fisurada, con desprendimiento de escamas, como lo describen AbundizBonilla et al. (2004) para la especie.

Características microscópicas de la corteza. En el estudio anatómico de ramas de $P$. laevigata libres de la epifita se aprecia una peridermis donde la felodermis está constituida generalmente de cinco hileras de células, mientras que el felema se compone de numerosos estratos que fácilmente se desprenden, aunque en algunas zonas se acumulan más de una peridermis y parches de floema secundario colapsado. Giménez et al. (2000) reportan para P. nigra 20 ó más hileras de células en la felodermis, con la formación de algunas esclereidas y un tejido suberoso escaso y poco desarrollado, con células de paredes poco engrosadas; en contraste, $P$. laevigata no presenta células pétreas en la felodermis y las paredes tangenciales del súber están más engrosadas que las radiales; los sacos secretores de sustancias gomosas pardas de origen traumático descritas por Giménez et al. (2000) en la peridermis tampoco fueron observados en las ramas de $P$. laevigata. Posiblemente caracteres anatómicos de la peridermis en tallos maduros puedan ser empleados como rasgos adicionales para distin- 
guir entre especies del género. A diferencia de lo que se ha observado en otras leguminosas (Roth, 1981; Orduño-Cruz y Terrazas, 1998), en las ramas estudiadas de $P$. laevigata no se observan lenticelas evidentes. Subyacente a la peridermis se presenta el córtex; éste forma parte del crecimiento primario de la rama, pero a diferencia de lo observado en las de Parkinsonia praecox con diámetros similares (Páez-Gerardo et al., 2005), en Prosopis laevigata no se aprecia la presencia de parénquima asimilador, ni aun en las ramas con diámetros de $1 \mathrm{~cm}$, como comúnmente se ha visto en la corteza de ramas jóvenes de otras especies (T. Terrazas, observaciones personales). Es muy probable que en $P$. laevigata este tejido sólo se conserve en ramillas menores de $1 \mathrm{~cm}$ de diámetro, perdiéndose tempranamente durante el desarrollo de la corteza. Por otro lado, comúnmente se observa en el córtex de $P$. laevigata células de parénquima que tienen forma rectangular alargada; esto se da como consecuencia del crecimiento secundario de la rama, que se manifiesta con una dilatación tangencial de las células (Strasburger, 1985). Además, en esta zona también se localizan conjuntos de células con las paredes que inician la acumulación de lignina en su pared secundaria. En esta tendencia del parénquima a esclerificarse algunas de ellas se desarrollan tempranamente en fibras y esclereidas, mientras que en otras este proceso es más tardío, como ocurre en las células que contienen cristales romboédricos, produciéndose en la parte más interna del córtex una banda continua de esclerénquima, formada por esclereidas, fibras y células esclerosadas, algunas con cristales romboédricos. Al respecto, Strasburger (1985) describe la formación de nuevo parénquima cortical secundario que se transforma en parte o totalmente en esclerénquima, originándose cilindros de sostén mixtos. En la región floemática, las bandas tangenciales de fibras, los radios ensanchados hacia el córtex y la presencia de cristales de oxalato de calcio, son caracteres que comparte $P$. laevigata con $P$. nigra (Giménez et al., 2000).

Cambios anatómicos de la corteza producidos por el esta blecimiento de Tillandsia recurvata. Con respecto a las zonas de las ramas donde crece $T$. recurvata, se determinó que ésta provoca dife rentes respuestas en la estructura anatómica de la corteza del mezquite. Éstas pueden ser imperceptibles y poco visibles, o por el contrario, ser conspicuas, como si se trat a ra de cicatrices dejadas por las raíces de la bromeliácea.

En los sitios donde interactúa $T$. recurvata con la rama de $P$. laevi gat $a$, en sección transversal, se distinguen claramente las raíces de la epifita, c u yas características anatómicas concuerdan con las descripciones realizadas por Segecin y Scatena (2004) para la especie. Este análisis nos permitió ap reciar que las alteraciones causadas en los tejidos de las ramas se deben a las raíces de la epifita y no a otro agente.

Aunque se aprecia que las raíces son superficiales y no penetran los tejidos de la rama del forofito, es evidente que hay cambios anatómicos en los tejidos de éste. Uno de los más comunes se da en la peridermis, ya que ésta desaparece, observándose en su lugar la acumulación de sustancias obscuras. Asimismo, hacia la zona del córtex, las células se colapsan mientras que otras se llenan de gran cantidad de contenido obscuro, además de la formación de esclerénquima. Esta región se separa de los tejidos más internos por la formación de súber interno. En numerosos trabajos se han reportado cambios anatómicos en la corteza como una respuesta a daños causados por diversos agentes patógenos que incluyen insectos (Franceschi et al., 1998, 2000), hongos (Robinson y Morrison, 2001; Nagy et al., 2004 2005; Hudgins et al., 2005) y microorganismos (Best y McManus, 2004). Estos cambios se refieren en la mayoría de los casos a un aumento de volumen celular, a la presencia de sustancias fenólicas y a la formación de peridermis de daño, entre otros. Estas alteraciones se presentan en los tejidos afectados de $P$. laevigata.

Otro de los cambios estructurales observados es la formación de peridermis de daño profundo en las ramas de $P$. laevigata. De acuerdo con Waisel (1995), los patógenos inducen la formación de peridermis profundas en las plantas que en condiciones normales (sanas) desarrollan peridermis superficial. Por otro lado, Bloch (1952) indica que en ambientes donde la humedad relativa es baja no se favorece la producción de peridermis de daño. Sin embargo, en $P$. laevigata ésta se ori gina en capas intermedias del córtex, y en ocasiones puede llegar al floema secundario colapsado.

Con respecto a las sustancias obscuras observadas en diferentes niveles de la corteza de P. laevigata, posiblemente se trate de compuestos fenólicos que también se forman en esta zona como una barrera química de resistencia a varias enfermedades, como se ha encontrado en otras especies (Waisel, 1995; Franceschi et al., 1998, 2000; Eyles et al., 2003; Nagy et al., 2004, 2005; Hudgins et al., 2005). Actualmente se está desarrollando un trabajo para identificar la naturaleza química de estas sustancias en $P$. laeviga ta.

En un solo caso la invaginación de la corteza modifica el patrón típico de la madera. Zimmermann (1983) registra que generalmente la madera responde ante la presencia de patógenos taponando los vasos con tilosas y gomas, pero en el forofito estudiado esto no fue observado. En P. laevigata fue evidente la hipertrofia del tejido, producida por la disminución drástica en el diámetro y el número de vasos y la pérdida del orden de las fibras. Los vasos angostos son mucho menos eficientes en la conducción hidráulica que los vasos amplios (Zimmermann, 1983). Esto, aunado a la escasez de estos elementos, seguramente conlleva a que en las áreas en donde se presentan las modificaciones se reduzca drásticamente el porcentaje del flujo del agua. Aunque este nivel de daño es raro, debe ocurrir cuando hay una interacción epifita-rama de mucho tiempo. 
La interacción. A pesar de que la mayoría de los autores ha subestimado el impacto que las epifitas pueden causar sobre sus forofitos, Benzing (1990) plantea la existencia de un parasitismo facultativo o epiparasitismo como una posibilidad en la relación epifita-forofito. El mismo autor menciona que algunas epifitas pueden dañar a los forofitos a través de varios mecanismos, como puede ser la producción de fitotoxinas, que conllevan a la defoliación de los hospederos, así como a la creación de condiciones que favorecen el ataque de patógenos a los tejidos de los hospederos. En este sentido, se llegaron a observar ocasionalmente restos de hifas creciendo en la interfase raíz-corteza del material estudiado, sin que se pudiera precisar su identidad ni su función. A este respecto, Benzing (1990) atribuye a algunos hongos asociados a las raíces de las plantas de Tillandsia una probable acción virulenta, transformando a la epifita en un reservorio de enfermedades infecciosas. Como respuesta las plantas pueden producir varios cambios estructurales y toxinas o metabolitos repelentes contra dicho fenómeno (Franceschi et al., 1998, 2000; Eyles et al., 2003; Nagy et al., 2004, 2005; Hudgins et al., 2005).

Por otra parte, Benzing (1990) menciona que muchos autores y él mismo suponen que nutrimentos disponibles en la superficie de la corteza son incorporados por las epifitas, pero en el caso de Tillandsia no se había encontrado alguna evidencia que apoyara esta idea. Sin embargo, el velamen bien desarrollado que se observó en las raíces de $T$. recurvata sugiere que estas plantas son capaces de absorber sustancias disponibles en los forofitos.

El desarrollo limitado de las raíces de epifitas como Tillandsia recurvata sobre sus hospederos fue descrito por Benzing (1990) como epifitismo extremo y en pocas ocasiones parece causar algún daño a los forofitos. Sin embargo, las raíces podrían acentuar el daño en la corteza de las ramas dependiendo de la abundancia de la epifita en ellas. Todos los cambios observados en la corteza por influencia de la epifita, dependiendo de su frecuencia y extensión, pueden repercutir en el intercambio gaseoso de la corteza, disminuyendo la movilización de $\mathrm{CO}_{2}$ en áreas disfuncionales y, a nivel de la madera, pueden afectar la movilización de agua y minerales.

\section{Agradecimientos}

Los autores agradecen a José García Franco el habernos invitado a participar en el proyecto "Incidencia y efecto de Tillandsia recurvata en Prosopis laevigata en la zona centro norte de México", a Alejandro Flores Palacios y Ascensión Capistrán-Barradas, su ayuda en la elección de localidades en San Luis Potosí; a Nayeli Libertad Echeveste Ramírez el apoyo brindado en el laboratorio y a Gustavo I. Labrada, el apoyo técnico en la preparación de las imágenes. También se agradece la revisión y los comentarios favorables de dos árbitros anónimos y a Jorge A.
Meave su valioso apoyo y sugerencias para la preparación final del manuscrito. El presente estudio fue financiado a través del Programa de Apoyo a los Profesores de Carrera para la formación de Grupos de Investigación (PAPCA) 2006 de la FES Iztacala, UNAM, y CONAFOR-SEMARNAT (2006-2007).

\section{Literatura citada}

Abundiz-Bonilla L.A.M., Barajas-Morales J. y Tenorio-Lezama P. 2004. Anatomía de Maderas de México: Árboles y Arbustos del Matorral Xerófilo de Tehuacán, Puebla. Instituto de Biología. Publicaciones Especiales 19. Universidad Nacional Autónoma de México. México, D.F.

Benzing D.H. 1990. Vascular Epiphytes: General Biology and Related Biota. Cambridge University Press, Cambridge.

Best M.V. y McManus S.P. 2004. Anatomy of cranberry stem gall and localization of bacteria in galls. Phytopathology 94:11721177.

Bloch, R. 1952. Wound healing in higher plants. Botanical Review 18:655-679.

Eyles A., Davies N.W., Yuan Z.Q. y Mohammed C. 2003. Host responses to natural infection by Cytonaema sp. in aerial bark of Eucalyptus globules. Forest Pathology 33:317-331.

Ffolliott P F. y Thames J.L. 1983. Manual sobre taxonomía de Prosopis en México, Perú y Chile. Organización de las Naciones Unidas para la Agricultura y la Alimentación. FAO, Roma, Departamento de Agricultura.

<www.fao.org/docrep/006/Q2580S/Q2580S00.HTM>

Franceschi R.V., Krekling T., Berryman A.A. y Christiansen E. 1998. Specialized phloem parenchyma cells in Norway spruce (Pinaceae) bark are an important site of defense reactions. American Journal of Botany 85:601-615.

Franceschi R.V., Krokene P., Krekling T. y Christiansen E. 2000. Phloem parenchyma cells are involved in local and distant defense responses to fungal inoculation or bark-beetle attack in Norway spruce (Pinaceae). American Journal of Botany 87:314-326.

Galera M.F. 2000. Las Especies del Género Prosopis (Algarrobos) de América Latina con Especial Énfasis en Aquellas de Interés Económico. Talleres Gráficos de Graziani Gráfica. Buenos Aires.

García-Franco. J.G, Flores-Palacios A., Capistran A.B., AguirreLeón E., Aguilar-Rodríguez S. y Huidobro-Salas M.E. 2007. Incidencia y efecto de Tillandsia recurvata sobre Prosopis lae vigata en la zona semiárida del Centro-Norte de México. Informe Final (mayo 2006- febrero 2007). Departamento de Ecología Funcional, Instituto de Ecología A.C., 64 p.

Giménez A.M., Moglia G., Hernández P. y Bravo S. 2000. Leño y la corteza de Prosopis nigra (Griseb.) Hieron, Mimosaceae, en relación a algunas magnitudes dendrométricas. Revista Forestal Venezolana 44:29-37.

Hudgins J.W., McDonald G.I., Zambino P.J., Klopfenstein N.B. y Franceschi V.R. 2005. Anatomical and cellular responses of Pinus monticola stems tissues to invasion by Cronartium ribi cola. Forest Pathology 35:423-443.

IAWA Committee. 1989. IAWA list of microscopic features for hardwood identification. International Association of Wood Anatomists Bulletin New Series 10:219-332. 
Johansen D.A. 1940. Plant Microtechnique. McGraw-Hill. Nueva York.

Leica Microsystems. 2002. Leica Qwin. Digital imaging systems for professional microscopy Leica. Imagic Bildverarbeitung AG, Wetzlar, Alemania.

Montaña C., Dirzo R. y Flores A.1997. Structural parasitism of an epiphytic bromeliad upon Cercidium praecox in an intertropical semiarid ecosystem. Biotropica 29:517-521.

Nagy N.E., Gunnar F.C, Krokene P., Krekling T., Lönneborg A. y Solheim H. 2004. Induced responses to phatogen infection in Norway spruce phloem: changes in polyphenolic parenchyma cells, chalcone synthese transcript levels and peroxidase activity. Tree Physiology 24:505-515.

Nagy N.E., Franceschi V.R., Kvaalen H. y Solheim H. 2005. Callus cultures and bark from Norway spruce clones show similar cellular features and relative resistance to fungal pathogens. Trees 19:695-703.

Orduño-Cruz A. y Terrazas T. 1998. Anatomía de la corteza de tres especies de leguminosas I. Origen y desarrollo. Boletín de la Sociedad Botánica de México 63:51-65.

Páez-Gerardo L.E. 2005. Biología de Tillandsia recurvata L. (Bromeliaceae) y su importancia en aplicaciones prácticas y ecológicas. Tesis de Licenciatura, Facultad de Estudios Superiores Iztacala. Universidad Nacional Autónoma de México. Tlalnepantla, Edo. de México. 82 pp.

Páez-Gerardo L.E., Aguilar-Rodríguez S., Terrazas T., Huidobro-
Salas M.E. y Aguirre-León E. 2005. Cambios anatómicos en la corteza de Parkinsonia praecox (Ruiz et Pavón) Hawkins causados por la epífita Tillandsia recurvada L. (Bromeliaceae). Boletín de la Sociedad Botánica de México 77:59-64.

Robinson M.R. y Morrison D.J. 2001. Lesion formation and host response to infection by Armillaria ostoyae in the roots of western larch and Douglas-fir. Forest Pathology 31:371-385.

Roth I. 1981. Structural Patterns of Tropical Barks. Encyclopedia of Plant Anatomy. Gebrüder Borntraeger, Berlín.

Samaniego A. 2002 Tillandsia recurvata: relación con la textura de las ramas de Prosopis laevigata. Biotropica 24:402-407.

Segecin S. y Scatena V.L. 2004. Morfoanatomía de rizomas e raízes de Tillansia L. (Bromeliaceae) dos Campos Gerais, PR, Brasil. Acta Botanica Brasilica 18:253-260.

Strasburger, E. 1985. Tratado de Botánica. $7^{\mathrm{a}}$. Ed. Marín. Barcelona.

Trockenbrodt M. 1990. Survey and discussion of the terminology used in bark anatomy. International Association of Wood Anatomists Bulletin New Series 11:141-166.

Waechter J.L. 1998. Epifitismo vascular em uma floresta de restinga do Brasil subtropical. Ciência e Natura 20:43-66.

Waisel Y. 1995. Developmental and functional aspects of the periderm. En: Iqbal M. Ed. The Cambial Derivatives. pp. 293-315. Encyclopedia of Plant Anatomy. Gebrüder Borntraeger, Berlín.

Zimmermann, H.M. 1983. Xylem Structure and the Ascent of Sap. Springer Series in Wood Science. Springer-Verlag. Berlín.

Recibido: 14 de agosto de 2007

Aceptado: 12 de noviembre de 2007 